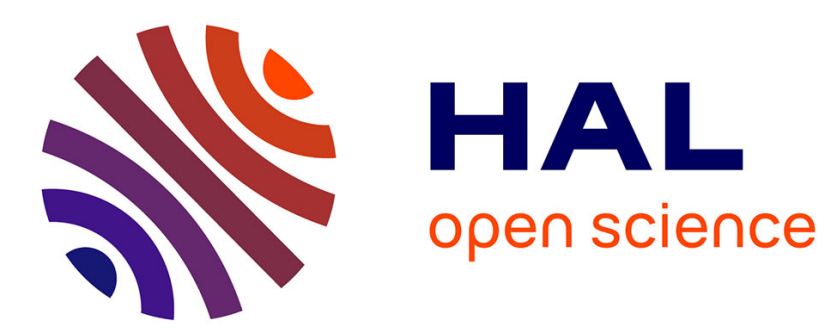

\title{
The realized niche of captive-hatched Houbara Bustards translocated in Morocco meets expectations from the wild
}

\author{
Anne-Christine Monnet, Yves Hingrat, Frédéric Jiguet
}

\section{To cite this version:}

Anne-Christine Monnet, Yves Hingrat, Frédéric Jiguet. The realized niche of captive-hatched Houbara Bustards translocated in Morocco meets expectations from the wild. Biological Conservation, 2015, 186, pp.241-250. 10.1016/j.biocon.2015.03.013 . hal-03027711

\section{HAL Id: hal-03027711 \\ https://hal.science/hal-03027711}

Submitted on 27 Nov 2020

HAL is a multi-disciplinary open access archive for the deposit and dissemination of scientific research documents, whether they are published or not. The documents may come from teaching and research institutions in France or abroad, or from public or private research centers.
L'archive ouverte pluridisciplinaire HAL, est destinée au dépôt et à la diffusion de documents scientifiques de niveau recherche, publiés ou non, émanant des établissements d'enseignement et de recherche français ou étrangers, des laboratoires publics ou privés. 
The realized niche of captive-hatched Houbara Bustards translocated in Morocco meets expectations from the wild

\author{
Anne-Christine Monnet ${ }^{1,2}$ \\ Yves Hingrat ${ }^{2,3}$ \\ Frédéric Jiguet $^{1}$ \\ ${ }^{1}$ Centre d'Écologie et des Sciences de la Conservation (CESCO UMR 7204), \\ Sorbonne Universités, MNHN, CNRS, UPMC, CP51, 55 rue Buffon, 75005 Paris, France \\ ${ }^{2}$ Emirates Center for Wildlife Propagation, PO Box 47, 33250 Missour, Morocco \\ ${ }^{3}$ RENECO for Wildlife Preservation, PO Box 61741, Abu Dhabi, U.A.E.
}

Corresponding author: Anne-Christine Monnet

Phone: +33140798007

Fax: +331407938 35

E-mail: acmonnet@mnhn.fr 


\section{Abstract}

2 The success of translocation programs aiming to boost the effective population size of a declining species is conditioned by the ability of released individuals to survive and breed effectively while they share the ecological niche of wild individuals. Although ecological niche models are increasingly used as tools for conservation translocations, the realized niche of released and wild populations is seldom compared. In this study, we used data from long-term monitoring of a reinforced population of Houbara Bustards in Morocco. We compared the patterns of use of ecological space in the wild by 446 captive-hatched individuals which settled for breeding with the patterns shown by the wild population from the monitoring of 233 wildhatched adult breeders. We measured the between-sex similarity of the ecological niches and of the geographical distributions. We found that wild-hatched and captive-hatched individuals shared a large part of the ecological space, suggesting a successful integration of captivehatched mature individuals. The wild-hatched individuals used a broader range of environmental conditions, driven by females that were, on average, older than captive-hatched females and dispersed toward more arid environments. Although the wild- and captive-hatched males had different geographical distributions, they had statistically equivalent ecological niches. This finding suggests that the released Houbaras succeeded in settling new lekking grounds within a similar ecological niche over a larger spatial extent. Such feedback from postrelease monitoring is still rare and appears to be a critical validation step for the subsequent use of ENM in translocation programs to assess the quality of release sites. 


\section{Keywords:}

22 Adaptive management

23 Captive breeding

24 Chlamydotis undulata

25 niche similarity

26 species distribution model

27 translocation

\section{Highlights:}

31 We compare the realized niche of translocated individuals with wild ecological niche.

32

Niche overlap is high between wild- and captive-hatched individuals.

34

Released males settle within the wild ecological niche over a larger extent.

We stress the importance of post-release monitoring within translocation programs. 


\section{Introduction}

Habitat suitability was identified early as a key parameter of success in conservation translocations (Wolf et al., 1998), the intentional movements and releases of a living organism(s) for conservation purposes (IUCN/SSC, 2013). Subsequently, the quantitative assessment of a species' ecological requirements has been advocated to select suitable release areas during the initial stages of a translocation project (Wolf et al., 1998). Because they are becoming increasingly easy to access and use on computing platforms, ecological niche models (ENMs, also called species distribution models when projected geographically) have rapidly become a complementary tool to assess the ecological requirements of species or the niche suitability of release areas. The fundamental niche of a species corresponds to the complete range of environmental conditions under which the populations of a species can thrive (Hutchinson, 1957). ENMs determine the part of the available environmental space that is actually occupied, the realized range, as an approximation of the fundamental niche of the species. At a time when climate change and its consequences for species distributions are becoming worldwide phenomena, this methodological framework has provided new perspectives for long-term conservation of biodiversity at the range-wide scale. Current or future projections of environmental suitability, including land use and climate, calibrated from remnant or historical distributions of species, can be directly used to select release areas.

Although ENMs are increasingly being proposed prior to release events, they are still rarely applied (Guisan et al., 2013), and there are few follow-up studies on the a posteriori use of modeled ecological space by released individuals. Nevertheless, the knowledge of the use of ecological space by released individuals can be very informative in translocation programs, as exemplified by post-release investigations on the ecological requirements of captive-hatched bearded vultures (Hirzel et al., 2004), which could guide future releases. Such examples of 
adaptive management remain scarce even though feedback from post-release monitoring can be critical to estimate reintroduction success (Armstrong et al., 2007; Seddon, 1999). In the case of population reinforcement, individuals are released into an existing population of conspecifics (IUCN/SSC, 2013) and we understand only poorly whether they use the same ecological niche as the reinforced population. This lack of information is a serious challenge, especially when released individuals are produced in captivity, because of several conflicting genetic processes: inbreeding depression, random genetic drift and adaptation to captivity (Ballou and Lacy, 1995; Chargé et al., 2014; Frankham, 2008, 2005; Neff et al., 2011), which are difficult to manage in supportive breeding. Maladaptive behavioral, morphological or physiological traits are expected to occur in released animals, that may affect their fitness in the wild (Araki et al., 2007; Blanchet et al., 2008; Champagnon et al., 2011; Ford, 2002). For example, Champagnon et al. (2010) found phenotypic changes in bill morphology after 30 years of Mallard restocking programs. Nevertheless, to our knowledge, genetic effects of captive breeding on sub-obtimal use of release environment have not yet been demonstrated. Comparisons of ecological requirements of released and wild populations are rare and have been generally focused on the local scale (Islam et al., 2013). To our knowledge, large-scale studies of ecological requirements of reinforced populations according to land-use patterns and bioclimatic envelope characteristics of the species have never been conducted. An appropriate post-release monitoring effort can furnish this missing step, which should shape the later use of niche projections.

In this study, we first modeled the distribution of wild-hatched individuals. We further compared the use of these environmental conditions characterizing the niche by captive-hatched individuals in the context of the reinforcement scheme for the North African Houbara Bustard (Chlamydotis undulata undulata, Otidiformes, Otididae; hereafter "Houbara"). The Houbara is 
a lekking bird that inhabits semi-desert steppes. It is red-listed as vulnerable to extinction by the International Union for Conservation of Nature because of a severe population decline caused primarily by overhunting and overgrazing (BirdLife International, 2014). Wild Houbara populations are intensively reinforced with captive-hatched individuals, primarily in eastern Morocco, by the Emirates Center for Wildlife Propagation (ECWP), which was initiated in 1995 (Lacroix, 2003). This translocation program provides a convenient framework, as we can model the ecological requirements of Houbaras based on presence data obtained on the wild population and compare these requirements with those obtained for captive-hatched individuals based on their post-release monitoring. The monitoring of individuals of both wild and translocated populations provides a unique opportunity within translocation programs. This program addresses a large number of translocated individuals from captive breeding and could thus generate pioneering studies to inform the translocation programs of species for which captive breeding or translocations face more stringent biological and technical limits.

Conservation translocations are primarily used with small or declining populations that are often locally extinct or restricted to refugial areas. As human activities can limit species distributions to suboptimal areas, the current distribution of a species may not indicate the only suitable habitats (Osborne and Seddon, 2012). Conversely, historical locations may no longer indicate suitable habitats (Osborne and Seddon, 2012). Modeling the ecological niche of species that are subjected to conservation translocations can thus be challenging. Moreover, a species does not necessarily occur in all suitable locations when ecological space is translated into geographical space. Therefore, we used two recently developed methods to complementarily compare the ecological niche of wild- and captive-hatched Houbaras. We measured the overlap between their ecological niches (Broennimann et al., 2012) to reveal a potential niche shift in released populations, independent of the sampling effort and of the spatial resolution of the 
environmental grid. To evaluate how similarity in ecological requirements translated into geographical space, we also measured the similarity of their geographical distributions using the method proposed by Godsoe (2014).

To identify and model environmental conditions used by both wild- and captive-hatched individuals, we compared the ecological requirements of mature individuals from their first breeding record onward, thus avoiding strong post-release effects associated with translocated, immature individuals (Hardouin et al., 2014). If captive-hatched individuals are suited to natural environmental conditions, we would expect them to occupy an ecological niche similar to that of wild-hatched individuals. Otherwise, a different use of the environmental space could have various explanations. A preferential use of a different part of the ecological niche would suggest a lack of adaptation of captive-hatched individuals to environmental conditions characterizing the niche of wild-hatched birds. A restricted use of the wild ecological niche could result from competition with remnant wild-hatched populations, potentially excluding released individuals from optimal portions of the niche. Because different sexes have different activities, often exhibit different dispersal strategies in lekking species (Morales et al., 2001) and can have different ecological requirements (Hingrat and Jalme, 2008), we also performed sex-specific analyses to test for potential different uses of the ecological niche by wild- and captive-hatched males and females. In this way, we assessed the amount of spatial and niche overlap of translocated captive-hatched individuals with the wild ecological niche. The results might help to evaluate the relevance of releases of captive-hatched individuals and to adjust translocation management practices. 


\section{Methods}

\subsection{Occurrence data}

138 We used data on the occurrences of both captured (wild-hatched) and translocated (captive139 hatched) Houbaras equipped with satellite or VHF transmitters in Eastern Morocco in an area 140 between $30^{\circ}$ and $34^{\circ} 17^{\prime} 30.012^{\prime} \prime \mathrm{N}$ latitude, $5^{\circ} 30^{\prime}$ and $0^{\circ} \mathrm{W}$ longitude (Figure 1 ).

142 Figure 1: Location of the study area in North Africa. Locations of pixels where wild143 hatched (gray circles) and captive-hatched (black circles) (a) female and (b) male Houbaras were recorded within the 2.5 arc-minutes (approximately $4.5 \mathrm{~km} \times 4.5 \mathrm{~km}$ ) grid of the Worldclim database.
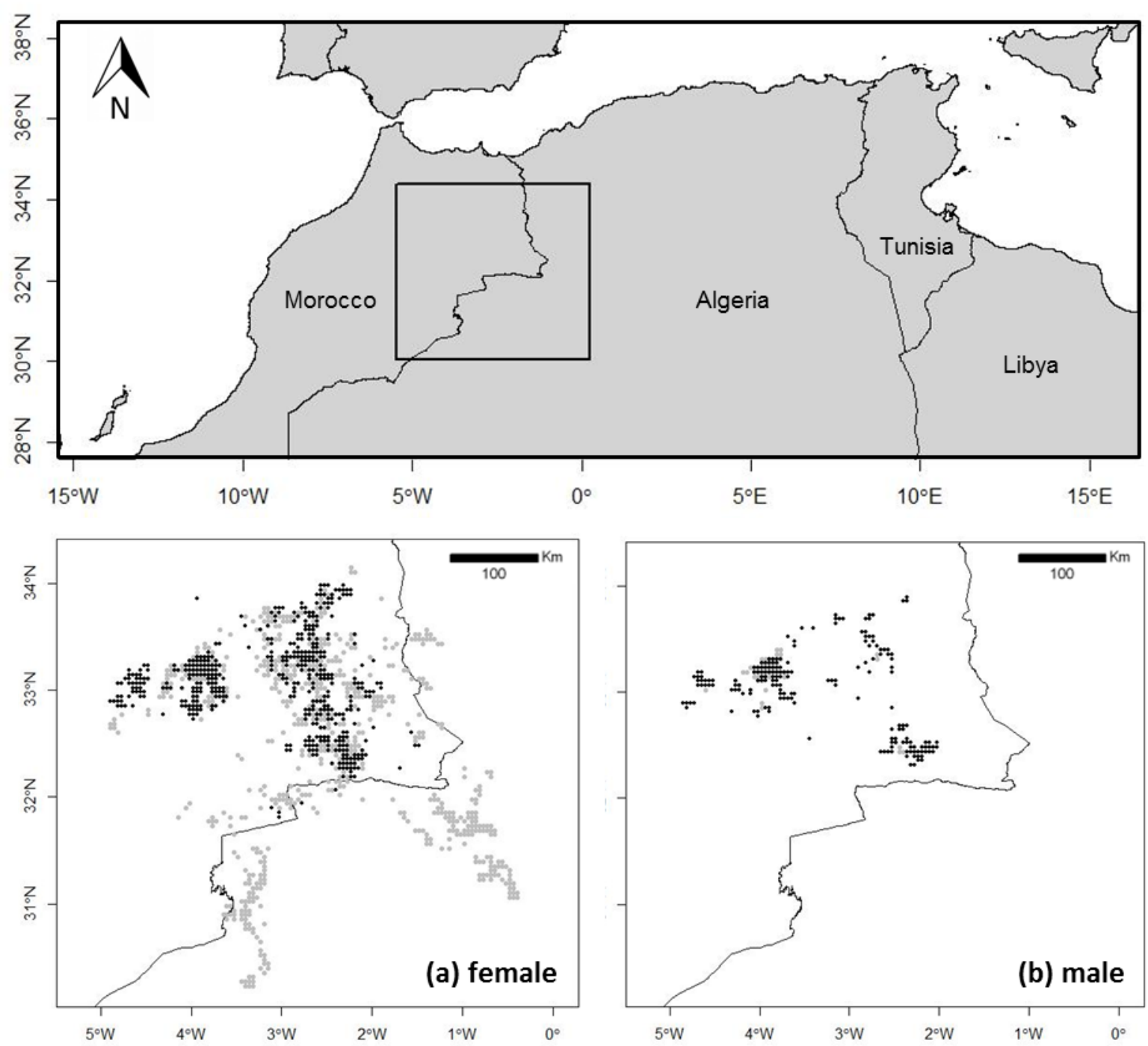


\subsubsection{Trapping of wild-hatched Houbaras}

The Emirates Center for Wildlife Propagation has performed trapping of adult Houbaras to study the behavior and ecology of wild populations of the Houbara since 1996 in Eastern Morocco during breeding seasons (Hingrat et al., 2004). Females were caught using nylon snares placed around the nest or surrounding wild-caught chicks (Launay et al., 1999; Seddon et al., 1999). For males, snares were placed around a live (from ECWP captive breeding) or dummy female on their displaying sites (Hingrat et al., 2004). Birds were banded with a unique metal leg band.

\subsubsection{Release of captive-hatched Houbaras}

Two ECWP breeding stations were established in Morocco for captive breeding (in Missour in 1995 and Enjil in 2005). A detailed description of the breeding program can be found in Lesobre et al. (2009) and Chargé et al. (2010, 2014). Before release, each individual was blood-sampled for molecular sexing and tagged with a metal ring up to the year 2006 and then tagged with a subcutaneous electronic micro-chip (Trovan ID100 Implantable Transponder, Dorset Group, Aalten, Netherlands).

Prior to the release, all birds were checked for disease by the ONSSA ("Office National de Sécurité Sanitaire des Produits Alimentaires"). All releases were recorded by the "HautCommissariat aux Eaux et Forêts et à la Lutte Contre la Désertification”. Houbaras were released during two periods: in autumn (from August to December) and in spring (from March to May). In autumn, Houbaras were primarily released in non-hunted areas to avoid direct mortality and disturbance due to hunting. The releases varied by site and group size (from 4 to 498 Houbara per release, median $=18$ ) over time. Houbaras were released at a mean age of (mean \pm SD) $247 \pm 113$ days. 


\subsubsection{Equipment and monitoring of satellite-monitored individuals}

175 The satellite transmitters used in this study were backpack solar-powered transmitters: PTT10030 or 45 g Solar GPS PTT (Microwave Telemetry, Inc., Columbia, Maryland, USA).

177 Satellite transmitters were programmed to collect data every two hours during daylight and to 178 download the data every $24 \mathrm{~h}$. To identify breeding events of individuals equipped with satellite transmitters, individuals' movements were checked. When stationary locations were recorded, the last location was checked in the field to confirm whether the individual was dead or a female was nesting.

\subsubsection{Equipment and monitoring of VHF radio-monitored individuals}

The VHF transmitters used in this study were battery-powered necklace units with mortality signals: 11 g model RI-2B-M, 20 g model RI-2D-M (Holohil System Ltd., Carp, Ontario, Canada) and 19 g solar-powered backpack (Merlin Systems Inc, Boise, Idaho, USA). From their release to 90 days ( \pm 10 days) post-release, VHF radio-equipped individuals were located twice a week. They were then located once a week (females) and every two weeks males. During the breeding seasons, VHF-equipped females were located twice a week. The activity of the females was observed with binoculars and telescopes to locate their nest. For the males, supplementary radiotracking sessions were conducted $3 \mathrm{~h}$ before sunrise and $2 \mathrm{~h}$ after sunset, when males perform their courtship, to locate their displaying site. Houbaras were primarily monitored from the ground at their last location within a radius buffer of $5 \mathrm{~km}$. Ground radiotracking was performed by direct observation from 4-wheel drive vehicles using a portable scanner-receiver and a 3-element Yagi antenna (AF Antronics, Inc., Urbana, Illinois, USA). If 
location. Aerial locations were taken from a Maule-7 B-235 aircraft using one 2-element Yagi antenna fixed to each wing strut. Houbaras were systematically sought during other aerial telemetry procedures (i.e., when searching for other "lost" birds). After six months without any relocations, an individual was considered "lost", and searching was suspended.

Table 1: Monitoring of wild- and captive-hatched Houbaras according to sex and to the type of transmitters: duration and number of $4.5 \mathrm{~km} \times 4.5 \mathrm{~km}$ pixels where individuals were recorded from their first known breeding site.

\begin{tabular}{cccccc} 
origin & transmitters & sex & $\begin{array}{c}\text { number of } \\
\text { individuals }\end{array}$ & $\begin{array}{c}\text { number of } \\
\text { pixels }\end{array}$ & $\begin{array}{c}\text { monitoring period from first breeding } \\
\text { (mean } \pm \text { SD, in days) }\end{array}$ \\
\hline \multirow{2}{*}{ captive-born } & satellite & female & 3 & 35 & $597 \pm 772$ \\
\cline { 2 - 6 } & \multirow{2}{*}{ VHF } & $\begin{array}{c}\text { female } \\
\text { male }\end{array}$ & $\begin{array}{c}348 \\
95\end{array}$ & $\begin{array}{c}428 \\
180\end{array}$ \\
\hline \multirow{3}{*}{ wild-born } & \multirow{2}{*}{ satellite } & female & 20 & 488 & $239 \pm 427$ \\
\cline { 2 - 6 } & \multirow{2}{*}{ VHF } & female & 120 & 406 & $982 \pm 701$ \\
& male & 93 & 56 & $1006 \pm 859$ \\
\hline
\end{tabular}

\subsubsection{Occurrence data from satellite and VHF radio-monitoring}

From 1998 to 2013, 233 adult wild-hatched and 3560 captive-hatched individuals were equipped with transmitters. The wild-hatched individuals were all adult breeders, as they were captured at their displaying site (93 males) or at their nest (120 females) (Table 1). Among captive-hatched Houbaras, we recorded breeding events (male in display, incubating/brooding female) for 446 individuals. Their first breeding event was recorded at a mean age of (mean \pm SD) $842 \pm 443$ days, and we considered only occurrences subsequent to the first breeding event (Table 1). Finally, for all individuals, we considered only occurrences during breeding seasons, from February to May. On average, Houbaras were monitored for two breeding seasons (mean \pm SD of monitoring duration for all individuals: $504 \pm 704$ days from the first known breeding event, details in Table 1). We assigned each occurrence, considering bird origin and sex, to its geographic location in the 2.5 arc-minute (approximately $4.5 \mathrm{~km} \times 4.5 \mathrm{~km}$ ) grid of the Worldclim database, removing the duplicated occurrences within each grid cell. In this way, 
we also reduced sampling bias due to the higher number of locations provided by satellite transmitters. These grids of presence were then used for ecological niche modeling and measures of niche overlap.

\subsection{Environmental data}

To describe the environmental space, we first chose a comprehensive set of 14 environmental predictors, previously used for Houbara distribution modeling (Monnet et al., 2014) and reflecting several key characteristics of the ecological niche of the species: bioclimatic, land cover, topographic and hydrological variables (a full list is available in Appendix A). We summarized these predictors according to the 2.5 arc-minute grid of the Worldclim database. We then used the method of Leroy et al. (2013) to select eight uncorrelated environmental predictors within the set of variables (methodological details in Appendix A): three bioclimatic variables (minimum temperature of the coldest month, maximum temperature of the warmest month, precipitation seasonality, Hijmans et al., 2005), the percentages of pixel covered by sandy desert, stony desert and sparse grassland (Mayaux et al., 2004), land cover heterogeneity based on the Shannon index, and the standard deviation of elevation (Jarvis et al., 2008).

\subsection{Ecological niche modeling}

We modeled ecological niches for six categories of birds separated by their origin and by their sex (Table 1): all wild-hatched, all captive-hatched, wild-hatched females, captive-hatched females, wild-hatched males and captive-hatched males. We performed an ensemble of seven modeling techniques using the biomod2 package (Thuiller et al., 2013) in R v3.0.1 (R Core Team, 2013): (1) generalized linear models (GLM), (2) generalized additive models (GAM), (3) generalized boosted models (GBM), (4) classification tree analysis (CTA), (5) artificial 
neural networks (ANN), (6) random forests (RF) and (7) multivariate adaptive regression splines (MARS). All of these modeling techniques require both presence and absence data. Because our datasets do not provide true absences, we generated 1000 artificial absence records (pseudo-absences) by randomly sampling from the grid cells of the whole study area. This approach by random sampling has recently been advocated in preference to the exclusion of pseudo-absences from spatial or environmental extents where presence occurrences were recorded (Barbet-Massin et al., 2012). Because different pseudo-absence samples can provide different results, we ran models for five pseudo-absence samples. Each model was calibrated on a random subset of $70 \%$ of the data and evaluated against the remaining $30 \%$ by crossvalidation. We replicated this data-splitting into "evaluation" and "calibration" subsets five times. We used the true skill statistic (TSS) (Allouche et al., 2006) to evaluate the predictive performance of each modeling technique. The final calibration of each model used $100 \%$ of the available data for making projections. Among the niche modeling techniques available and the high inter-model variability in predictive performance, consensus methods (or "ensemble forecasting") retain the central tendency given by different models and are preferred to singlemodel approaches because they provide the best predictive performance (Araújo and New, 2007; Marmion et al., 2009). We followed one of the most robust methods identified by Marmion et al. (2009) to provide ensemble predictions: we averaged the predictions of models from the seven modeling techniques, removing models below a TSS quality threshold of 0.5 . We calculated the mean values of TSS across pseudo-absence and data-splitting runs to evaluate the ensemble model. We calculated and mapped the coefficient of variation (i.e., SD/mean) of the models' predictions within the ensemble model as a measure of uncertainty.

\subsection{Measurement of the similarity of distributions}


From the predictions of models for wild- and captive-hatched individuals (separately for males and females, as well as for both sexes together), we compared the similarity of spatial distributions by calculating the expected fraction of shared presences (ESP), as recently proposed by Godsoe (2014). A generalization of Sørensen's similarity, the ESP ranges between 0 and 1.

\subsection{Measurement of ecological niche overlap}

To quantify the similarity in the ecological requirements of wild- and captive-hatched individuals, we calculated Schoener's D (Schoener 1968, reviewed by Warren et al. 2008), a measure of the amount of niche overlap within the environmental space, which varies from 0 (no overlap) to 1 (complete overlap). We then performed statistical tests of niche hypotheses (equivalency and similarity, Warren et al. 2008). To test a niche equivalency hypothesis, 100 datasets with the same initial number of occurrences were randomly drawn from the pool of all occurrences (considered separately for males, females, or both sexes and for captive- and wildhatched individuals). We then calculated the simulated values of D. If the observed value of D falls within the range of $95 \%$ of the simulated values, the null hypothesis cannot be rejected, and the niches are considered statistically equivalent (Broennimann et al., 2012). The niche similarity test, less conservative, determines whether niches are more similar than expected at random. We calculated the overlap between the niche of captive-hatched Houbaras and the randomly shifted density of occurrences of wild-hatched and vice versa. This process was repeated 1000 times. The null hypothesis (i.e., niches are no more similar to one another than expected at random) was rejected if the observed overlap was greater than $95 \%$ of the simulated values of overlap. 
294 Following Broennimann's analysis framework (2012), we computed these measures and tests

295 of niche overlap from the density estimates in environmental space to correct for bias related to

296 the availability of environmental space for the species. We then performed a principal 297 components analysis (PCA) directly from the occurrences of wild- and captive-hatched 298 individuals (separately for males, females, and for both sexes). The niche comparison was thus 299 independent of the niche modeling methods and of uncertainty in the predictions of species 300 distribution (Smith and Donoghue, 2010). The PCA was calibrated on the entire environmental 301 space of the study area (hereafter called PCA-env), the most robust approach selected by 302 Broennimann et al. (2012) to quantify the niche overlap. To describe the environmental space, 303 we used the same eight environmental variables that were selected for ecological niche 304 modeling. The scores of the occurrences on the first two axes of PCA-env were projected onto 305 a $100 \times 100$ grid, and a smoothed density of occurrences in environmental space was calculated using a kernel density function (using the default settings of Broennimann et al., 2012) to compare ecological niches independently of sampling effort and of the spatial resolution of the environmental grid. The measures and tests of niche overlap were performed from the script provided by Broennimann et al. (2012) in R v3.0.1 (R Core Team, 2013). 


\section{Results}

311

312

\subsection{Ecological niche modeling and similarity of distribution}

The mean values of the true skill statistic (TSS) across the seven modeling techniques of each of the six ensemble models were high (TSS: mean $=0.816 \pm 0.109)$. Figure 2 shows the predicted distributions of wild- and captive-hatched individuals from the ensemble models (i.e., the probability of presence). The uncertainty in each ensemble model, estimated from the coefficient of variation of the predictions of constituent models, is shown in Appendix B. The expected fraction of shared presence (ESP) between wild- and captive-hatched Houbaras was 0.425 for both sexes, 0.403 for females, and 0.258 for males.

\subsection{Ecological niche overlap}

The amount of niche overlap between wild- and captive-hatched Houbaras was high $(\mathrm{D}=$ 0.691). The hypothesis of niche equivalency was rejected: the difference between the niches was significant $(\mathrm{P}=0.0198)$. A two-way test of niche similarity showed that the niches of wildand captive-hatched Houbaras were more similar than expected by chance (similarity test, $\mathrm{P}<$ $0.01)$.

The first two PCA-env axes explained almost $60 \%$ of the total variation of environmental background. PCA-env showed a distribution of Houbaras structured according to the first axis (36.83\% variation explained) by a decreasing elevation gradient (associated, on average, with higher minimum and maximum temperatures and a lower proportion of open grassland) and according to the second axis (22.2\% variation explained) by an aridity gradient (associated, on average, with higher maximum temperatures, more precipitation seasonality, a higher proportion of sandy desert and a lower proportion of stony desert) (Figure 3 and Figure 4). While the environmental space was largely shared by wild- and captive-hatched Houbaras, a 
portion specific to the wild-hatched Houbaras was characterized by lower elevation and associated with higher minimum and maximum temperatures (axis 1) and a more arid environment (axis 2) (Figure 3 and Figure 4).

339 Sex-separated comparisons between wild- and captive-hatched Houbaras showed a higher 340 overlap for males $(D=0.858)$ than for females $(D=0.685)$. The niches of wild- and captive341 hatched males were statistically equivalent (equivalency test, $\mathrm{P}=0.36$ ) and more similar 342 than expected by chance (two-way test of similarity, $\mathrm{P}<0.01$ ). The niches of females were 343 not equivalent (equivalency test, $\mathrm{P}=0.0198$ ) but more similar than expected by chance (two344 way test of similarity, $\mathrm{P}<0.01)$. 
Figure 2: Predictions (probability of presence) of ecological niche models for

347 (a) wild-hatched (left) vs. captive-hatched (right) males and females

$348 \quad$ (b) wild-hatched (left) $v$ s. captive-hatched (right) females

349

(c) wild-hatched (left) vs. captive-hatched (right) males

WILD-born

(a)

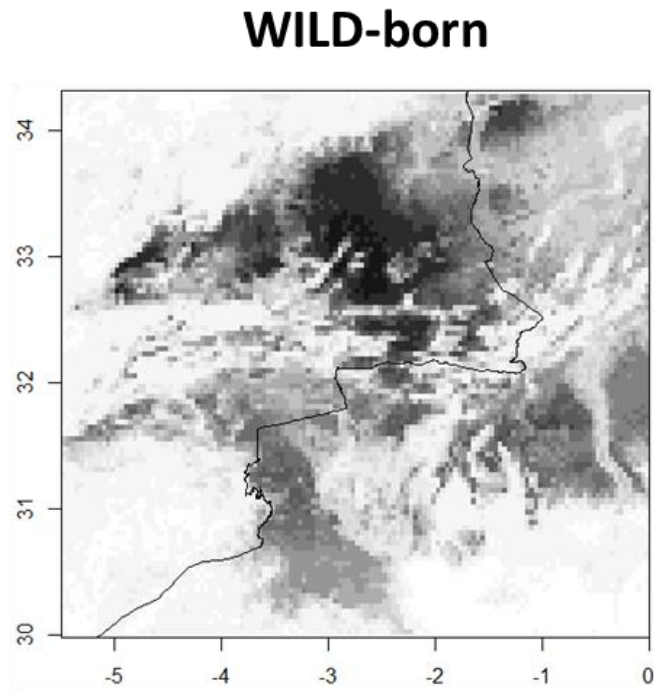

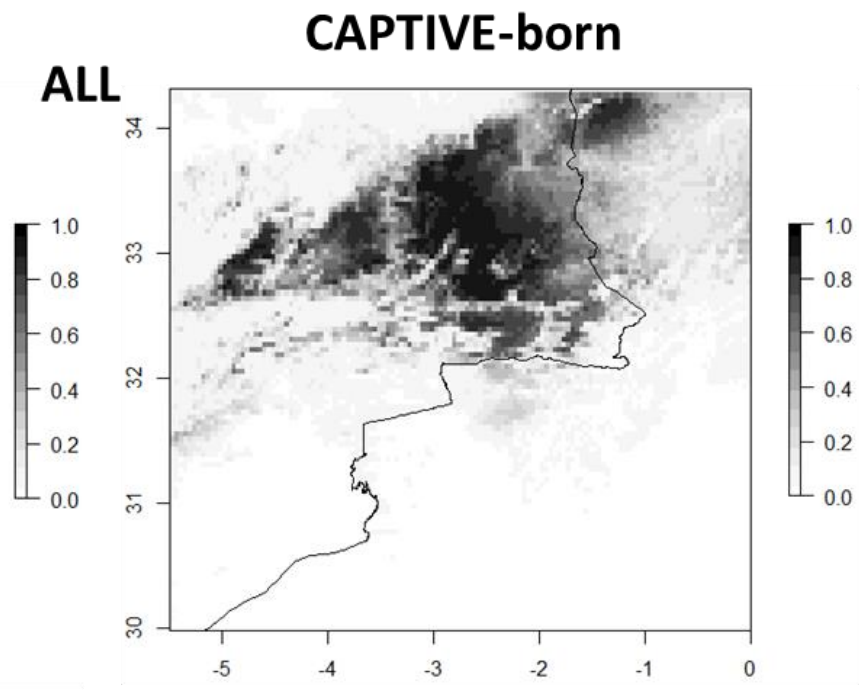

(b)
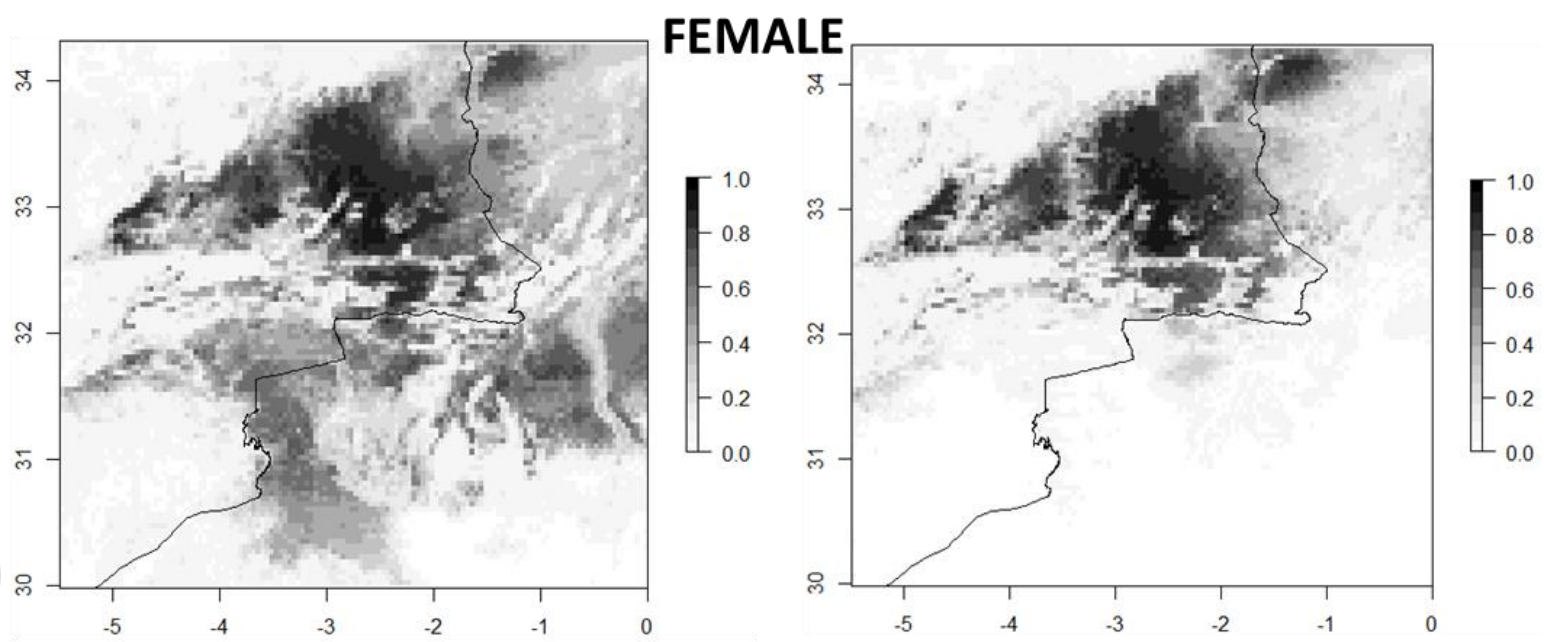

(c)

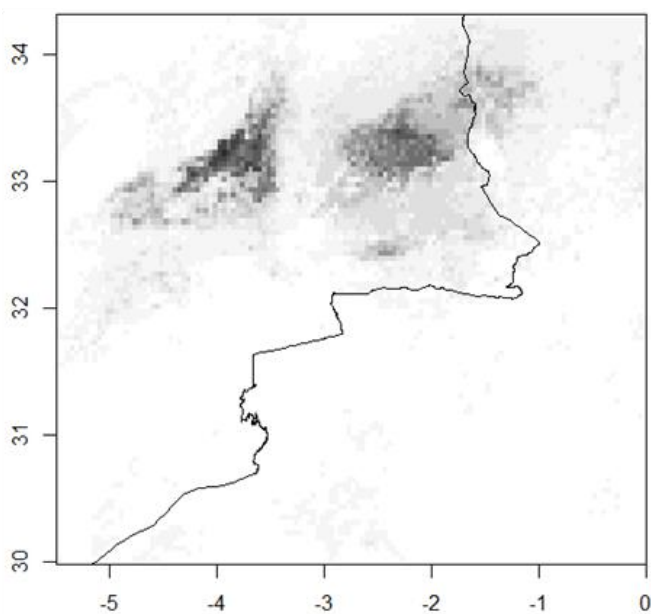

MALE

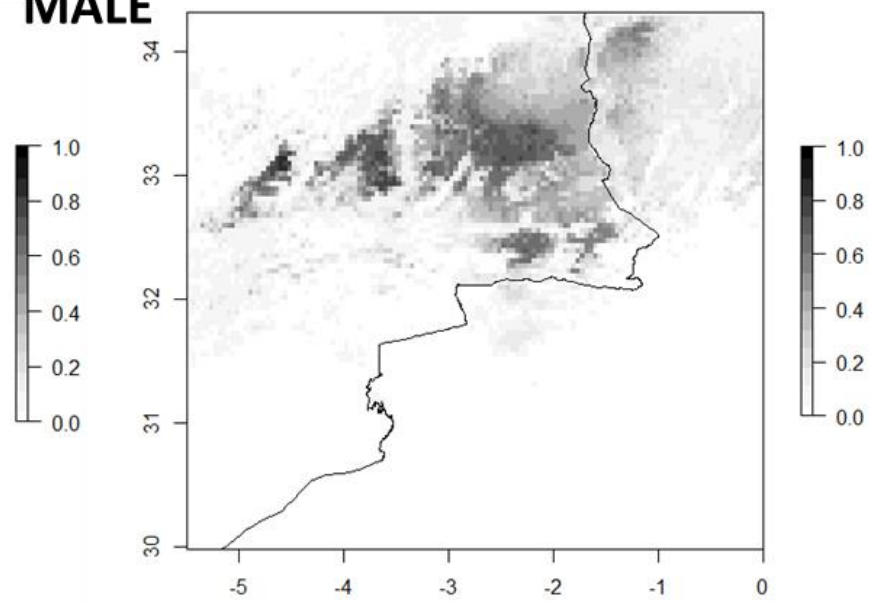


Figure 3: Comparison of the use of environment by wild- and captive-hatched Houbaras using a principal components analysis calibrated on environmental background (PCAenv) of smoothed density of occurrences (gray shading) of:

(a) wild-hatched (left) vs. captive-hatched (right) males and females

(b) wild-hatched (left) vs. captive-hatched (right) females

(c) wild-hatched (left) vs. captive-hatched (right) males

Solid and dotted lines correspond to $100 \%$ and $50 \%$ of the available environment space, respectively.

WILD-born
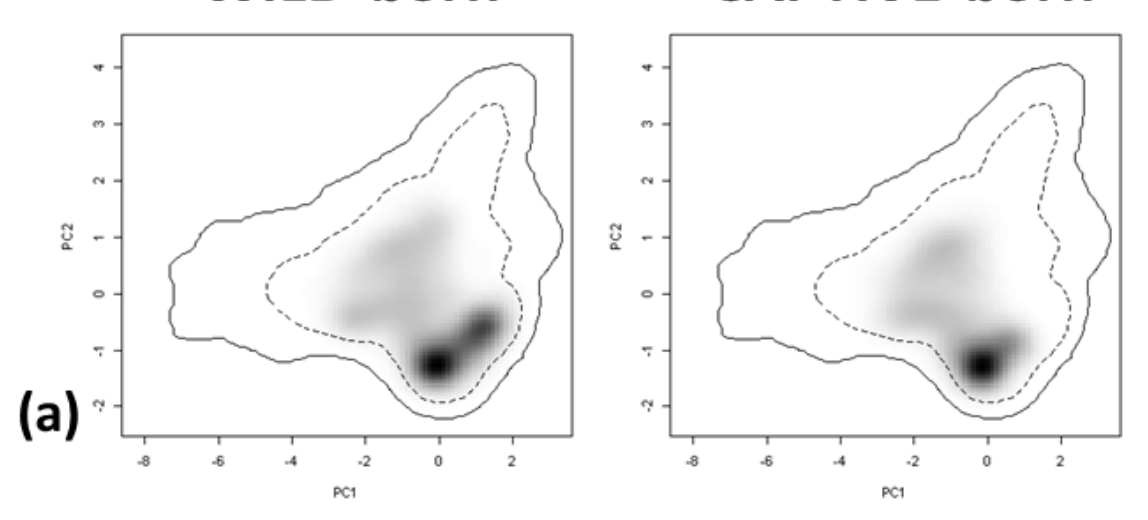

CAPTIVE-born
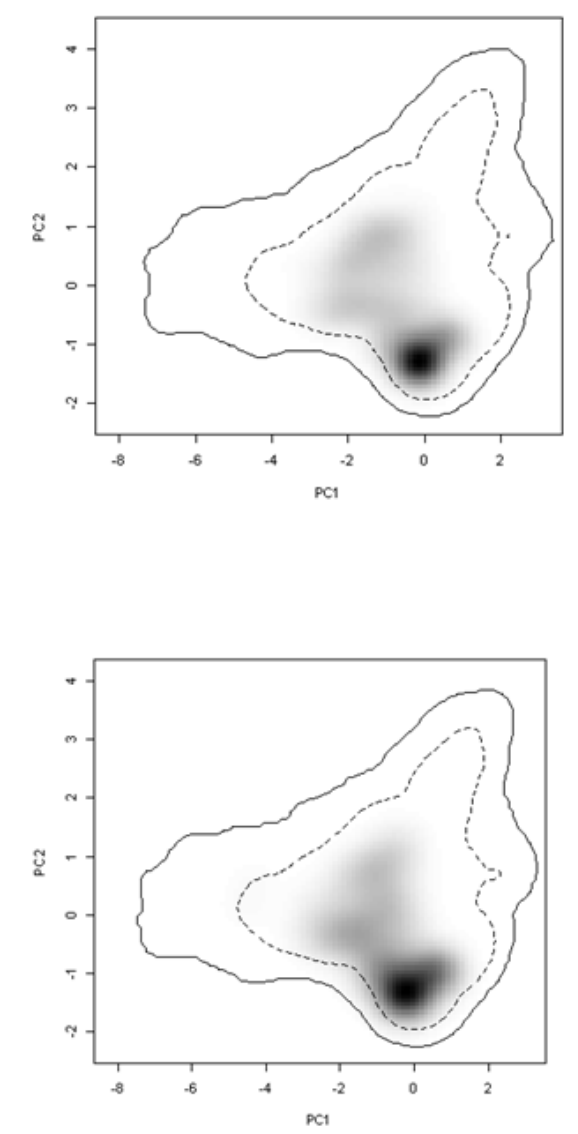

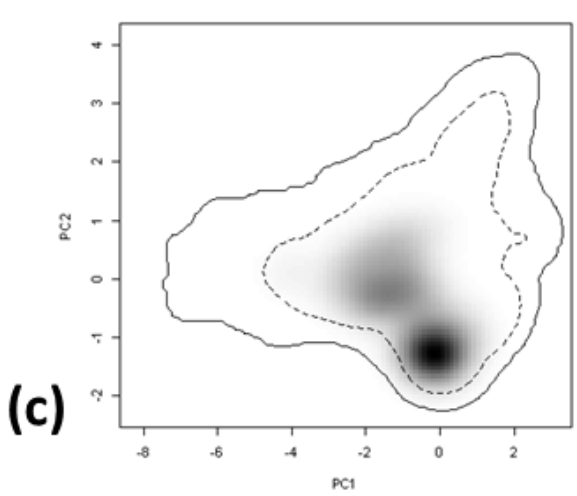


Figure 4: Loadings of environmental variables on the two first axes of the principal components analysis (PCA-env):

362 minimum ("bio6") temperature of the coldest month and maximum ("bio5") of the warmest month, precipitation seasonality ("bio15"), percentage of pixels covered by sandy desert, stony desert and sparse grassland ("sandy desert", "stony desert" and "grassland", respectively), Shannon's index ("Shannon"), and standard deviation of elevation ("elevation").

367

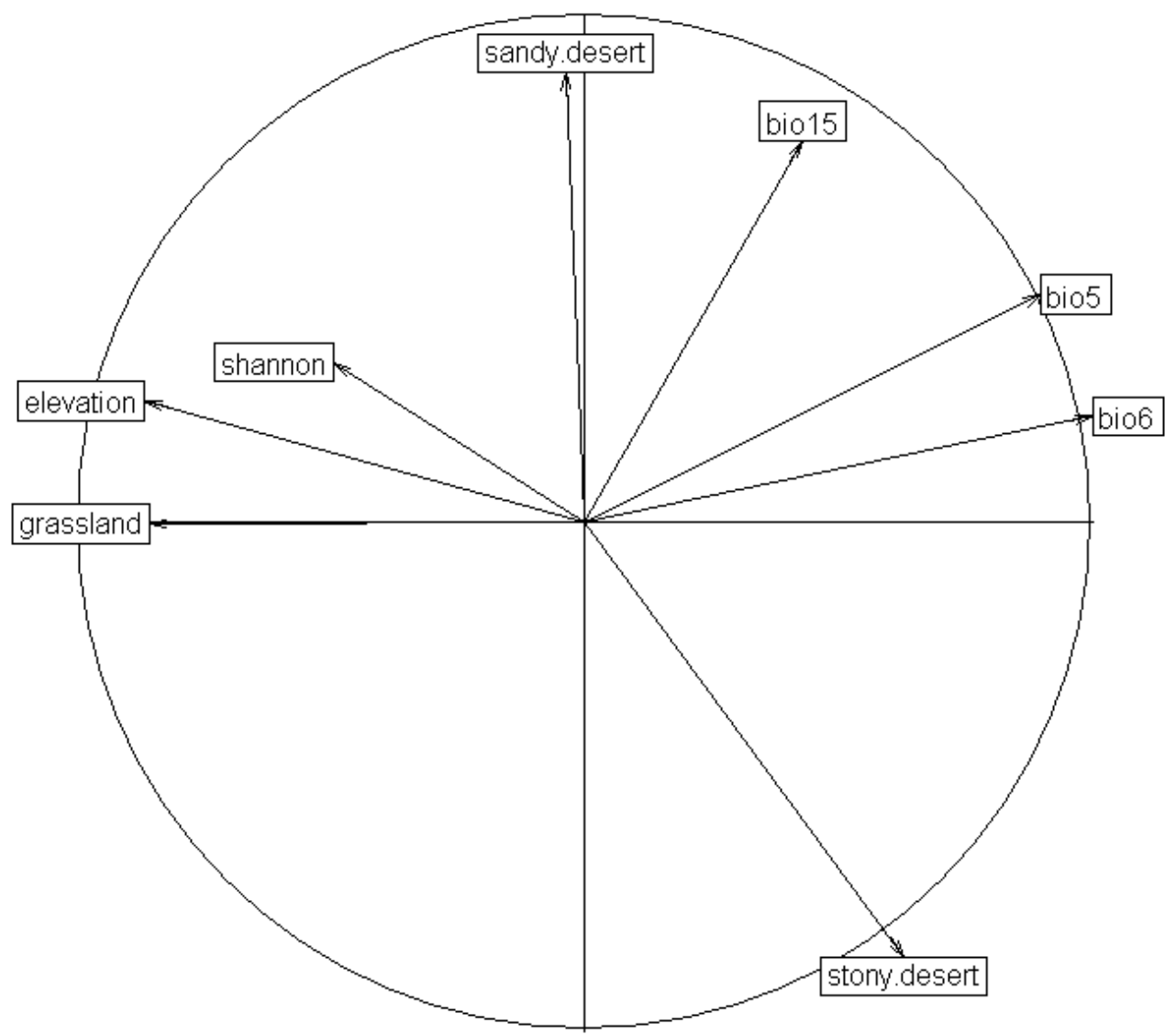




\section{Discussion}

370

371

372

Although Osborne \& Seddon (2012) advocated the use of predictions from niche models to assess the quality of potential release areas for conservation translocation programs, there are few assessments of the post-release use of the ecological niche of a species by translocated individuals of that species. This lack of information is primarily due to the difficulties of monitoring a large number of released individuals at large spatial and temporal scales. In this study, we benefited from monitoring data gathered from a large-scale long-term reinforcement program dedicated to the Houbara in Morocco (Hardouin et al., 2014; Lacroix, 2003), with hundreds of mature wild- and captive-hatched individuals tracked with radio or satellite transmitters, to model and compare the niches of wild-hatched and of captive-hatched translocated individuals. Niche models are usually developed using presence data, i.e., all locations where a species has been observed, with generally very few spatial replicates for the same individual, but they are also efficient when using the tracks of marked individuals, e.g., if the same individual provides a large number of presence locations (Jiguet et al., 2010). Using tracks is also a way to partly avoid biases due to heterogeneous sampling effort and the varying detection probability of a species across different habitats and spatial areas.

We first modeled the ecological niche of the wild-hatched individuals, using bioclimatic, land cover, and topographic variables. We projected this ecological space onto the geographical space. By further studying the use of this 'wild' ecological niche by captive-hatched released individuals, we found that wild- and captive-hatched individuals share a large part of the species ecological space: their niches are statistically similar, although they are not equivalent. Assessing the patterns of use of ecological space in the wild of released individuals should be a critical step in the case of reinforcement programs, which aim to reintegrate captive-hatched individuals in small or declining wild populations. A niche shift between captive- and wild- 
hatched individuals could potentially ensue from different evolutionary processes affecting the fundamental niche, such as differences in genetic diversity, evolution of competitive ability or hybridization (Blossey \& Nötzold 1995), which may arise from the pool of captive-bred birds, or from different outcomes of biotic interactions affecting the realized niche (e.g., Keane \& Crawley 2002; Dietz \& Edwards 2006).

We found that captive-hatched Houbaras use the ecological niche similarly to wild-hatched individuals: their respective modeled niches are more similar than expected by chance, with a high level of overlap, a pattern also found for males and females when analyzed separately. A difference in biotic constraints on captive- and wild-hatched individuals, e.g., in terms of predation, competition, parasitism, or pathogens, could result in differences between the modeled niches of the two group (Wisz et al., 2013). Here, we can hypothesize that the outcomes of biotic interactions shaping the realized niche of wild- and captive-hatched individuals do not differ, at least for individuals who survived to maturity. Indeed, within the reinforcement program considered in this study, the release sites of captive-hatched individuals initially hold relict wild populations (Figure 1, Appendix C). However, even though captivehatched individuals survive and breed in the wild, when faced with biotic constraints similar to those of wild-hatched individuals, captive-born released individuals could have responded differently. To our knowledge, empirical evidence showing such differences in an established population benefiting from long-term monitoring is lacking. In this case of population reinforcement, captive-hatched individuals might encounter high intraspecific competition at release sites because of the presence of other released congeners or of wild-hatched individuals. However, the modeled niche of captive-hatched individuals does not reflect competitive exclusion by wild-hatched individuals. The niche core, i.e., the area of higher density of niche use, of captive-hatched individuals is consistent with the niche core of wild-hatched individuals 
(Figure 3a), with an especially strong match for males. The realized niche of captive-hatched individuals was thus not restricted to a peripheral part of the ecological space but is clearly included in the realized niche of wild-hatched individuals. This finding suggests that the captive-hatched individuals who survived the immediate post-release mortality peak among the release cohort and settled to breed adapt successfully to the environmental conditions that are associated with wild-hatched individuals.

Although the observed niches of wild- and captive-hatched Houbaras are more similar than expected by chance, they are not statistically equivalent. Indeed, although wild- and captivehatched Houbaras share a large part of the environmental space, the ecological niche of wildhatched individuals encompasses a wider range of environmental conditions (see Figure 3a, showing a niche core for wild-hatched individuals that is not shared by captive-hatched individuals). A part of the ecological niche specific to wild-hatched females is characterized, on average, by higher minimum and maximum temperatures and a more arid environment (Figure $3 b$ and Figure 4). These differences in the use of ecological space might be explained, at least in part, by potential differences in the age of wild- and captive-hatched individuals. As captive-hatched females are released during their first year of life, we at least recorded their first known breeding events as young mature adults (first breeding record event at $842 \pm 443$ days, mean $\pm \mathrm{SD}$ ), whereas wild-hatched females may have bred several times before being captured, equipped and monitored. At the first known breeding event, the wild-hatched individuals of our sample are, thus, expected to be, on average, older than the captive-hatched individuals. Although female Houbaras do not show high natal dispersal (Hardouin et al. 2012 in wild-hatched, Hardouin et al. 2014 in captive-hatched individuals), they disperse farther from year to year between their breeding attempts (breeding dispersal), which results in a larger lifelong range of use within geographic and environmental spaces by older birds. Furthermore, 
the wider use of available environmental conditions by wild-hatched individuals might have been successfully demonstrated because females were tracked with satellite transmitters. Satellite transmitters ensure monitoring over large dispersal distances without relying on terrestrial or aerial telemetry, as required for VHF transmitters, and notably beyond the southern Moroccan border toward the more arid Saharan climate. Interestingly, no captive-hatched females equipped with satellite transmitters used these hotter and more arid desert environments where wild-hatched females dispersed. However, the satellite sample for captive-hatched females was smaller than for wild-hatched females.

\section{We found a higher similarity of ecological niche between wild- and captive-hatched males than} between females. Likewise, the ecological niches of wild- and captive-hatched males were more similar than expected by chance, and the same was the case for the ecological niches of wildand captive-hatched females. In addition, niche overlap was higher between males than between females ( $D=0.858$ between wild- and captive-hatched males vs. $D=0.685$ between females), and, unlike the niches of females, those of wild- and captive-hatched males were statistically equivalent. Because males and females perform different activities during breeding seasons and, thus, different ecological requirements (Hingrat and Jalme, 2008), we expected such contrasting responses. Just as in other lekking species, natal dispersal is sex-biased in Houbara: males exhibit longer dispersal distances than females (Hardouin et al., 2012). From their first breeding onwards, males are partially territorial, concentrating their activities around their display sites and exhibiting high year-to-year fidelity to their display sites (Hingrat et al., 2004). Nonetheless, the low expected fraction of shared presence (ESP $=0.258$ between wild- and captive-hatched males) suggests that although their ecological requirements were similar, they were distributed differently in the geographic space. Wild-hatched males were primarily captured in the steppe areas of a plain called Al Baten, a protected area where the largest 
remnant wild Houbara population is found and where captive-hatched individuals were not released (Appendix C). These results suggest a successful establishment of new lekking grounds by captive-hatched translocated Houbaras, which settled within a similar ecological niche in an area with a greater geographical extent.

\section{Conclusions}

We propose an analysis framework, based on the recent developments of metrics to compare species ecological requirements (Broennimann et al., 2012; Godsoe, 2014), to assess the postrelease use of translocated individuals using ecological niche models. First, this framework provides a post-release evaluation of translocation programs. If projections from niche modeling are more often integrated in the assessment of potential release sites, they must be tested experimentally or empirically. The Houbara reinforcement scheme considered here is a pioneering system to test the efficacy of niche models to evaluate the niche wilderness of released individuals based on an impressive number of released individuals and on an extensive monitoring effort. We found no exclusion of mature captive-bred individuals from optimal parts of the ecological space used by wild-born individuals. A comparison of the breeding success of the same two groups within the ecological space remains to be performed to complete the evaluation of the translocation program. Finally, we stress the importance of such feedback from adequate post-release monitoring as a validation step for the subsequent use of niche modeling for pre-release planning in translocation programs. Our analysis framework may then provide a relevant feedback to adapt release planning. For instance, in the case of the Houbara Bustard in North Africa, future releases could occur in sites with predicted ecological requirements similar to those of wild birds, whether or not a remnant wild population presence was recently recorded. 
494 This study was funded by the Emirates Center for Wildlife Propagation (ECWP), a project of 495 the International Fund for Houbara Conservation (IFHC). We are grateful to H. H. Sheikh 496 Mohammed bin Zayed Al Nahyan, Crown Prince of Abu Dhabi and Chairman of the IFHC and 497 H. E. Mohammed Al Bowardi, Deputy Chairman of IFHC, for their support. This study was 498 conducted under the guidance of RENECO for Wildlife Preservation, a consulting company 499 managing ECWP. We are thankful to Dr. F. Lacroix, managing director, and G. Levèque, 500 project director, for their supervision. We sincerely thank all ECWP staff from the Ecology and 501 Release divisions who participated in data collection. Particular thanks go to S. Boullenger, E.

502 Le Nuz, C. Lucas and L. Hardouin for their efficiency in dataset preparation. We also thank B. 503 Leroy for his help with the selection of environmental variables for niche modeling. 
Allouche, O., Tsoar, A., Kadmon, R., 2006. Assessing the accuracy of species distribution models: prevalence, kappa and the true skill statistic (TSS). J. Appl. Ecol. 43, 1223-1232. doi:10.1111/j.1365-2664.2006.01214.x

Araki, H., Cooper, B., Blouin, M.S., 2007. Genetic effects of captive breeding cause a rapid, cumulative fitness decline in the wild. Science 318, 100-3. doi:10.1126/science.1145621

Araújo, M.B., New, M., 2007. Ensemble forecasting of species distributions. Trends Ecol. Evol. 22, 42-7. doi:10.1016/j.tree.2006.09.010

Armstrong, D.P., Castro, I., Griffiths, R., 2007. Using adaptive management to determine requirements of re-introduced populations: the case of the New Zealand hihi. J. Appl. Ecol. 44, 953-962. doi:10.1111/j.1365-2664.2007.01320.x

Ballou, J.D., Lacy, R.C., 1995. Identifying genetically important individuals for management of genetic variation in pedigreed populations, in: J. D. Ballou, M. Gilpin, T.J.F. (Ed.), Population Management for Survival and Recovery. pp. 76-111.

Barbet-Massin, M., Jiguet, F., Albert, C.H., Thuiller, W., 2012. Selecting pseudo-absences for species distribution models: how, where and how many? Methods Ecol. Evol. 3, 327-338. doi:10.1111/j.2041-210X.2011.00172.x

BirdLife International, 2014. Chlamydotis undulata. The IUCN Red List of Threatened Species. Version 2014.2. [WWW Document]. URL <www.iucnredlist.org>

Blanchet, S., Páez, D.J., Bernatchez, L., Dodson, J.J., 2008. An integrated comparison of captive-bred and wild Atlantic salmon (Salmo salar): Implications for supportive breeding programs. Biol. Conserv. 141, 1989-1999. doi:10.1016/j.biocon.2008.05.014

Blossey, B., Nötzold, R., 1995. Evolution of increased competitive ability in invasive nonindigenous plants: a hypothesis. Ecology 83, 887-889.

Broennimann, O., Fitzpatrick, M.C., Pearman, P.B., Petitpierre, B., Pellissier, L., Yoccoz, N.G., Thuiller, W., Fortin, M.-J., Randin, C., Zimmermann, N.E., Graham, C.H., Guisan, A., 2012. Measuring ecological niche overlap from occurrence and spatial environmental data. Glob. Ecol. Biogeogr. 21, 481-497. doi:10.1111/j.1466-8238.2011.00698.x

Champagnon, J., Guillemain, M., Elmberg, J., Folkesson, K., Gauthier-Clerc, M., 2010. Changes in Mallard Anas platyrhynchos bill morphology after 30 years of supplemental stocking. Bird Study.

Champagnon, J., Guillemain, M., Elmberg, J., Massez, G., Cavallo, F., Gauthier-Clerc, M., 2011. Low survival after release into the wild: assessing "the burden of captivity" on Mallard physiology and behaviour. Eur. J. Wildl. Res. 58, 255-267. doi:10.1007/s10344-011-0573-3

Chargé, R., Saint-Jalme, M., Lacroix, F., Cadet, A., Sorci, G., 2010. Male health status, signalled by courtship display, reveals ejaculate quality and hatching success in a lekking species. J. Anim. Ecol. 79, 843-50. doi:10.1111/j.1365-2656.2010.01696.x 
Chargé, R., Sorci, G., Saint Jalme, M., Lesobre, L., Hingrat, Y., Lacroix, F., Teplitsky, C., 2014. Does recognized genetic management in supportive breeding prevent genetic changes in life-history traits? Evol. Appl. 7, 521-532. doi:10.1111/eva.12150

Dietz, H., Edwards, P., 2006. Recognition that causal processes change during plant invasion helps explain conflicts in evidence. Ecology 87, 1359-1367.

Ford, M.J., 2002. Selection in Captivity during Supportive Breeding May Reduce Fitness in the Wild. Conserv. Biol. 16, 815-825. doi:10.1046/j.1523-1739.2002.00257.x

Frankham, R., 2005. Genetics and extinction. Biol. Conserv. 126, 131-140. doi:10.1016/j.biocon.2005.05.002

Frankham, R., 2008. Genetic adaptation to captivity in species conservation programs. Mol. Ecol. 17, 325-33. doi:10.1111/j.1365-294X.2007.03399.x

Godsoe, W., 2014. Inferring the similarity of species distributions using Species' Distribution Models. Ecography (Cop.). 37, 130-136. doi:10.1111/j.1600-0587.2013.00403.x

Guisan, A., Tingley, R., Baumgartner, J.B., Naujokaitis-Lewis, I., Sutcliffe, P.R., Tulloch, A.I.T., Regan, T.J., Brotons, L., McDonald-Madden, E., Mantyka-Pringle, C., Martin, T.G., Rhodes, J.R., Maggini, R., Setterfield, S. a, Elith, J., Schwartz, M.W., Wintle, B. a, Broennimann, O., Austin, M., Ferrier, S., Kearney, M.R., Possingham, H.P., Buckley, Y.M., 2013. Predicting species distributions for conservation decisions. Ecol. Lett. 16, 1424-1435. doi:10.1111/ele.12189

Hardouin, L., Nevoux, M., Robert, A., Gimenez, O., Lacroix, F., Hingrat, Y., 2012. Determinants and costs of natal dispersal in a lekking species. Oikos 121, 804-812. doi:10.1111/j.16000706.2012.20313.x

Hardouin, L.A., Robert, A., Nevoux, M., Gimenez, O., Lacroix, F., Hingrat, Y., 2014. Meteorological conditions influence short-term survival and dispersal in a reinforced bird population. J. Appl. Ecol. n/a-n/a. doi:10.1111/1365-2664.12302

Hijmans, R.J., Cameron, S.E., Parra, J.L., Jones, P.G., Jarvis, A., 2005. Very high resolution interpolated climate surfaces for global land areas. Int. J. Climatol. 25, 1965-1978. doi:10.1002/joc.1276

Hingrat, Y., Jalme, M. Saint, 2008. Environmental and social constraints on breeding site selection. Does the exploded-lek and hotspot model apply to the Houbara bustard Chlamydotis undulata. J. Avian Biol. 393-404. doi:10.1111/j.2008.0908-8857.03994.x

Hingrat, Y., Saint-Jalme, M., Ysnel, F., Lacroix, F., Y, J.S., Rautureau, P., Seabury, J., 2004. Relationships between home-range size, sex and season with reference to the mating system of the Houbara Bustard Chlamydotis undulata undulata. Ibis (Lond. 1859). 146, 314-322. doi:10.1111/j.1474-919X.2004.00263.x

Hirzel, A.H., Posse, B., Oggier, P.-A., Crettenand, Y., Glenz, C., Arlettaz, R., 2004. Ecological requirements of reintroduced species and the implications for release policy: the case of the bearded vulture. J. Appl. Ecol. 41, 1103-1116. doi:10.1111/j.0021-8901.2004.00980.x

Hutchinson, G.E., 1957. Concluding Remarks. Cold Spring Harb. Symp. Quant. Biol. 22, 415-427. doi:10.1101/SQB.1957.022.01.039 
Islam, M.Z., Singh, a., Basheer, M.P., Judas, J., Boug, a., 2013. Differences in space use and habitat selection between captive-bred and wild-born houbara bustards in Saudi Arabia: results from a long-term reintroduction program. J. Zool. 289, 251-261. doi:10.1111/jzo.12002

IUCN/SSC, 2013. Guidelines for Reintroductions and Other Conservation Translocations. Version 1.0. Gland, Switzerland.

Jarvis, A., Reuter, H., Nelson, A., Guevara, E., 2008. Hole-filled SRTM for the globe Version 4 available from the CGIAR-CSI SRTM 90m Database at http://cgiar-csi.org/.

Jiguet, F., Barbet-Massin, M., Chevallier, D., 2010. Predictive distribution models applied to satellite tracks: modelling the western African winter range of European migrant Black Storks Ciconia nigra. J. Ornithol. 152, 111-118. doi:10.1007/s10336-010-0555-3

Keane, R., Crawley, M., 2002. Exotic plant invasions and the enemy release hypothesis. Trends Ecol. Evol. 17, 164-170.

Lacroix, F., 2003. The Emirates Center for Wildlife Propagation: developing a comprehensive strategy to secure a self sustaining population of Houbara bustards in eastern Morocco. Houbara News 5, 2.

Launay, F., Combreau, O., Aspinall, S., 1999. Trapping of Breeding Houbara Bustard (" Chlamydotis Undulata"). Wildl. Soc. ... 27, 603-608.

Leroy, B., Paschetta, M., Canard, A., Bakkenes, M., Isaia, M., Ysnel, F., 2013. First assessment of effects of global change on threatened spiders: Potential impacts on Dolomedes plantarius (Clerck) and its conservation plans. Biol. Conserv. 161, 155-163. doi:10.1016/j.biocon.2013.03.022

Lesobre, L., Lacroix, F., Caizergues, A., Hingrat, Y., Chalah, T., Saint Jalme, M., 2009. Conservation genetics of Houbara Bustard (Chlamydotis undulata undulata): population structure and its implications for the reinforcement of wild populations. Conserv. Genet. 11, 1489-1497. doi:10.1007/s10592-009-9979-9

Marmion, M., Parviainen, M., Luoto, M., Heikkinen, R.K., Thuiller, W., 2009. Evaluation of consensus methods in predictive species distribution modelling. Divers. Distrib. 15, 59-69. doi:10.1111/j.1472-4642.2008.00491.x

Mayaux, P., Bartholomé, E., Fritz, S., Belward, A., 2004. A new land-cover map of Africa for the year 2000. J. Biogeogr. 31, 861-877. doi:10.1111/j.1365-2699.2004.01073.x

Monnet, A.-C., Hardouin, L.A., Robert, A., Hingrat, Y., Jiguet, F., 2014. Evidence of a link between demographic rates and species habitat suitability from post release movements in a reinforced bird population. Oikos. doi:10.1111/oik.01834

Morales, M.B., Jiguet, F., Arroyo, B., 2001. Exploded leks: what bustards can teach us. Ardeola 48, 85-98.

Neff, B.D., Garner, S.R., Pitcher, T.E., 2011. Conservation and enhancement of wild fish populations: preserving genetic quality versus genetic diversity. Can. J. Fish. Aquat. Sci. 68, 1139-1154. doi:10.1139/f2011-029 
Osborne, P.E., Seddon, P.J., 2012. Selecting suitable habitats for reintroductions: variation, change and the role of Species Distribution Modelling, in: Reintroduction Biology: Integrating Science and Management. p. 528.

R Core Team, 2013. R: A language and environment for statistical computing.

Seddon, P.J., 1999. Reintroductions, introductions, and the importance of post-release monitoring: lessons from Zanzibar. Oryx 33, 89-97.

Seddon, P.J., Launay, F., van Heezik, Y., Al Bowardi, M., 1999. Methods for live trapping houbara bustards. J. F. Ornithol 70, 169-181.

Smith, S. a, Donoghue, M.J., 2010. Combining historical biogeography with niche modeling in the Caprifolium clade of Lonicera (Caprifoliaceae, Dipsacales). Syst. Biol. 59, 322-41. doi:10.1093/sysbio/syq011

Thuiller, W., Georges, D., Engler, R., 2013. biomod2: Ensemble platform for species distribution modeling.

Warren, D.L., Glor, R.E., Turelli, M., 2008. Environmental niche equivalency versus conservatism: quantitative approaches to niche evolution. Evolution (N. Y). 62, 2868-83. doi:10.1111/j.15585646.2008.00482.x

Wisz, M.S., Pottier, J., Kissling, W.D., Pellissier, L., Lenoir, J., Damgaard, C.F., Dormann, C.F., Forchhammer, M.C., Grytnes, J.-A., Guisan, A., Heikkinen, R.K., Høye, T.T., Kühn, I., Luoto, M., Maiorano, L., Nilsson, M.-C., Normand, S., Öckinger, E., Schmidt, N.M., Termansen, M., Timmermann, A., Wardle, D. a, Aastrup, P., Svenning, J.-C., 2013. The role of biotic interactions in shaping distributions and realised assemblages of species: implications for species distribution modelling. Biol. Rev. Camb. Philos. Soc. 88, 15-30. doi:10.1111/j.1469185X.2012.00235.X

Wolf, C.M., Jr, T.G., Griffith, B., 1998. Predictors of avian and mammalian translocation success: reanalysis with phylogenetically independent contrasts. Biol. Conserv. 86. 


\section{Supplementary material}

\section{Appendix A - Environmental data}

\section{1) Initial pool of environmental predictors}

\section{- 8 bioclimatic variables}

1) mean annual temperature (BIO1)

2) minimum temperature of the coldest month (BIO6)

3) maximum temperature of the warmest month (BIO5)

4) temperature seasonality (standard deviations of mean monthly temperatures) (BIO4)

5) annual precipitation (BIO12)

6) precipitation of the driest month (BIO14)

7) precipitation of the wettest month (BIO13)

8) precipitation seasonality (coefficient of variation of monthly precipitations) (BIO15) from the Worldclim database (Hijmans et al. 2005).

\section{- 1 topographic variable}

We calculated the standard deviation of elevation from the CIGAR-CSI SRTM $250 \mathrm{~m}$ database within each grid cell (Jarvis et al. 2008). It is expressed in meters and varies from 0 to 529.9 meters.

\section{- 1 hydrological variable}

We calculated the mean annual soil water stress from the monthly soil water stress provided by CGIAR-CSI Global Soil-Water Balance Database with a resolution of 30 arc-seconds (i.e., approximately 920 meters at the equator) (Trabucco \& Zomer 2010). The mean annual soil water stress describes the mean annual fraction of soil water content available for evapotranspiration processes (expressed as a percentage).

\section{- 4 land cover variables}

We selected the three main land cover classes of the study area (Figure 1) from the Global Land Cover of Africa (1 km² pixel resolution; Mayaux et al. 2003):

(1) sandy desert,

(2) stony desert,

(3) sparse grassland.

We calculated the percentage covered by these three classes within each cell of the environmental grid in the study area.

We calculated the Shannon index of land cover heterogeneity in each grid cell of the study area from the percentage of each Global Land Cover classes.

2) Selection of intercorrelated variables significantly predicting the distribution (method of Leroy et al. 2013) 
First, we identified two groups of intercorrelated variables using a Pearson correlation coefficient:

1) $\mathrm{BIO6}, \mathrm{BIO} 14$

2) $\mathrm{BIO} 1, \mathrm{BIO} 4, \mathrm{BIO} 5, \mathrm{BIO} 12, \mathrm{BIO} 13$, mean annual soil water stress

We then calibrated all modeling techniques with these two groups of variables and ran the variable importance procedure of the BIOMOD function. For each group, we then selected the variable with the highest mean importance among all the models:

1) $\mathrm{BIO6}$

2) $\mathrm{BIO5}$

Finally, we retained eight uncorrelated variables. Each retained variable represents one group of intercorrelated variables:

- minimum temperature of the coldest month (BIO6)

- maximum temperature of the warmest month (BIO5)

- precipitation seasonality (coefficient of variation of monthly precipitations) (BIO15)

- \% of pixel covered by sandy desert

- \% of pixel covered by stony desert

- \% of pixel covered by sparse grassland

- Shannon index of land cover

- standard deviation of elevation

\section{References}

Global Land Cover 2000 Project, http://bioval.jrc.ec.europa.eu/ products/glc2000/glc2000.php

Hijmans, R.J., Cameron, S.E., Parra, J.L., Jones, P.G. \& Jarvis, A. 2005 Very high resolution interpolated climate surfaces for global land areas. International Journal of Climatology 1978, 1965-1978. (doi:10.1002/joc.1276)

Jarvis, A., Reuter, H.I., Nelson, A. \& Guevara, E. 2008 Hole-filled SRTM for the globe Version 4, available from the CGIAR-CSI SRTM 90 m Database at http://www.cgiar-csi.org

Mayaux P., Bartholomé E., Massart M. et al. 2003 A land cover map of Africa. European Comission, Joint Research Center Publications Reposery, EUR 20665 EN

Monnet, A.-C., Hardouin, L.A., Robert, A., Hingrat Y., Jiguet, F. Evidence of a link between demographic rates and species habitat suitability from post release movements in a reinforced bird population. Oikos DOI: 10.1111/oik.01834

Trabucco, A., \& Zomer, R.J. 2010. Global Soil Water Balance Geospatial Database. CGIAR Consortium for Spatial Information. Published online, available from the CGIAR-CSI GeoPortal at http://www.cgiar-csi.org 
Appendix B - Map of the uncertainty in ecological niche modeling
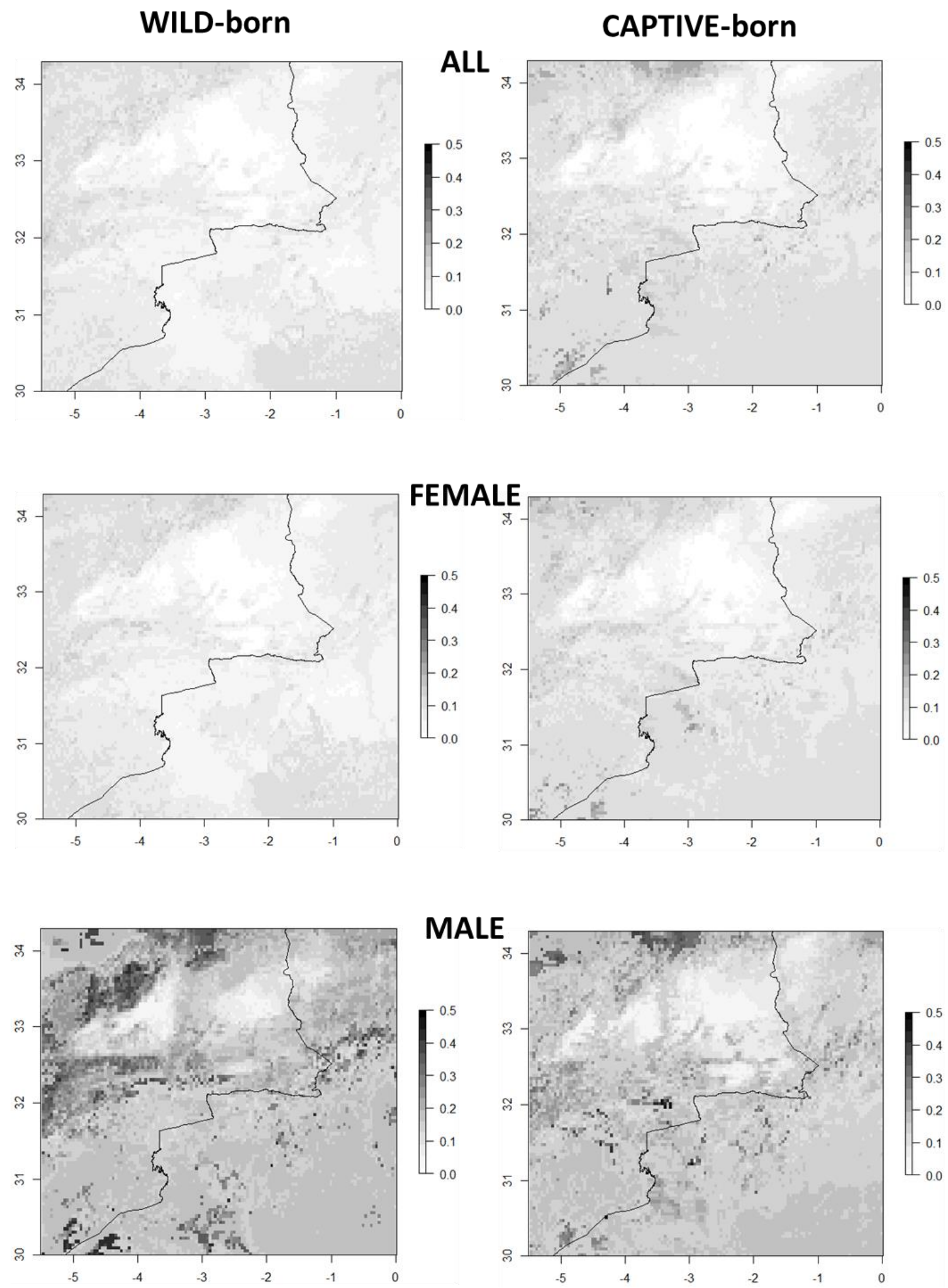


\section{Appendix C - Map of the release and capture sites}

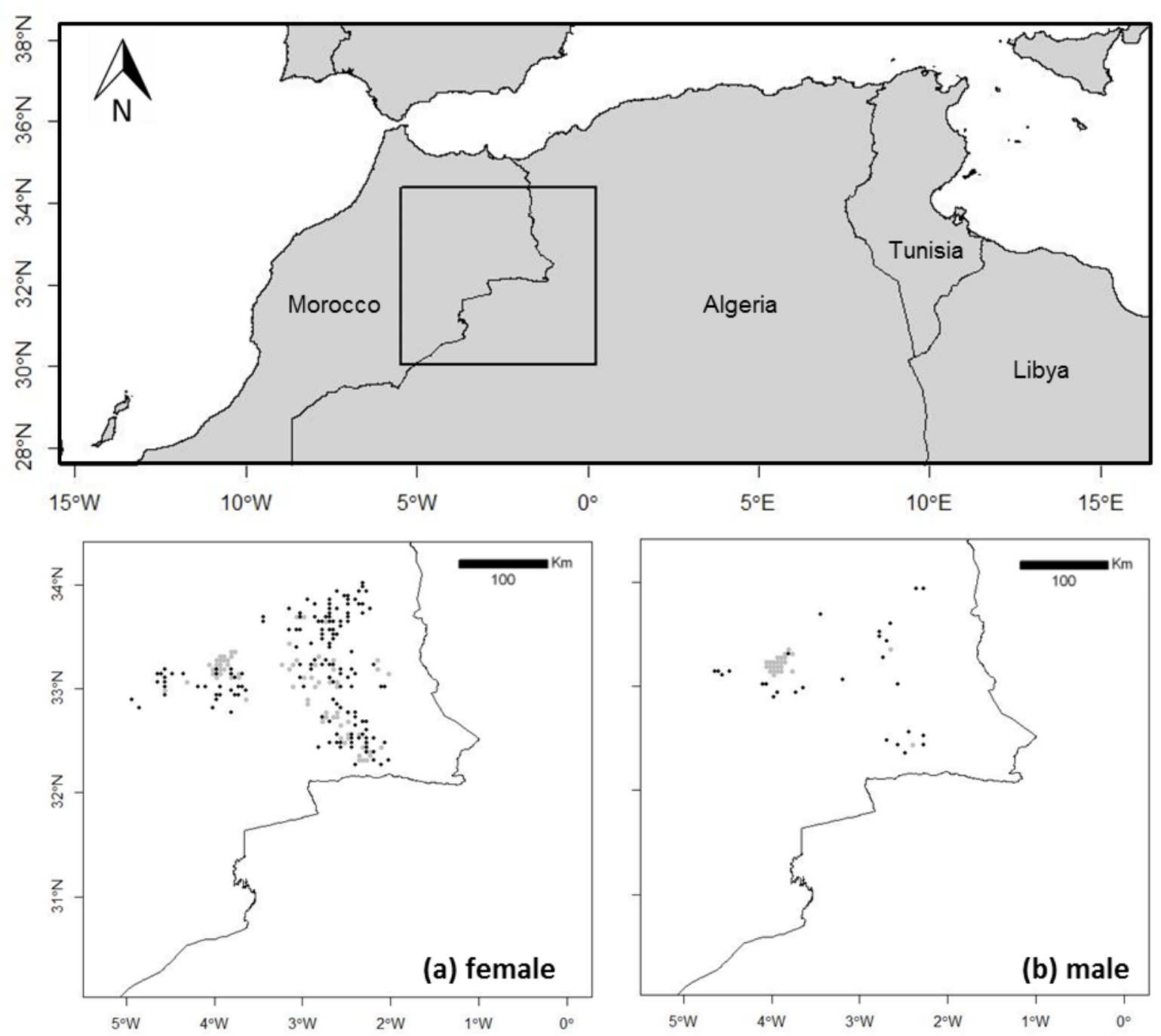

Location of the study area in North Africa. Locations of capture sites of wild-hatched (gray circles) and release sites of captive-hatched (black circles) (a) female and (b) male Houbara.

Wild-hatched males (gray circles) were captured primarily in the Al Baten area (centered at $33.23^{\circ} \mathrm{N}-03.94^{\circ} \mathrm{W}$ ). 